Талипов Н.Г., Катасёв А.С.

\title{
ПРОГРАММНЫЙ КОМПЛЕКС РАСПРЕДЕЛЕНИЯ ЗАДАНИЙ В АВТОМАТИЗИРОВАННЫХ СИСТЕМАХ ЭЛЕКТРОННОГО ДОКУМЕНТООБОРОТА НА ОСНОВЕ НЕЧЕТКИХ МЕТОДОВ ПРИНЯТИЯ РЕШЕНИЙ
}

\begin{abstract}
Аннотация: Предметом исследования является оценка эффективности распределения заданий по исполнителям в автоматизированных системах электронного документооборота на основе нечетких методов рачионального выбора альтернатив. Объектом исследования является задача рационального выбора исполнителей с учетом их квалификации, работоспособности, загруженности, а также сложности поступающих на распределение заданий. В работе рассматриваются три стратегии распределения заданий: на основе метода максиминной свертки, аддитивной свертки и нечетко-продукционной модели. Особое внимание уделяется программному комплексу, разработанному на базе предложенных методов. Приводится пример его функционирования, а также результаты проведенных исследований по оценке эффективности распределения заданий по исполнителям. В качестве методов исследования используются нечеткие методы рационального выбора альтернатив: максиминной свертки, аддитивной свертки и нечетко-продукционный метод. Данные методы используются для распределения заданий по исполнителям в автоматизированных системах электронного документооборота. Основными выводами проведенного исследования являются:- метод на основе нечеткого логического вывода показал лучшие результаты, наиболее точно согласующиеся с интуитивным представлением эксперта по рациональному выбору исполнителей заданий;- метод максиминной свертки является пессимистичным подходом, не учитывающим хорошие стороны альтернатив; - метод аддитивной свертки реализует оптимистичный подход, в котором низкие оченки по критериям имеют одинаковый вес по сравнению с высокими оценками, что повлияло на его низкую точность.Особым вкладом авторов в исследование темы является разработка эффрективной нечетко-продукционной модели распределения заданий, а также реализация программного комплекса, позволившего выполнить необходимые исследования по оценке ее эффективности. Это определяет научную новизну и практическую ченность проведенного исследования.
\end{abstract}

Ключевые слова: система электронного документооборота, распределение заданий, принятие решений, нечетко-продукционная модель, программный комплекс, метод максиминной свертки, метод аддитивной свертки, рациональный выбор альтернатив, нечеткий логический вывод, оператор персональных данных 
Abstract: The subject of the study is to evaluate the effectiveness of assigning tasks in the automated systems of electronic document management on the basis of fuzzy methods of rational choice of alternatives. The object of the research is the problem of a rational choice of employee for the task based on qualifications, performance, workload as well as difficulty of the assignment. The paper focuses on three job assignment strategies: based on the method of maximin convolution, additive convolutions and fuzzy-production model. Particular attention is paid to the software developed on the basis of the proposed methods. The authors present an example of its operation, as well as the results of studies evaluating the effectiveness of allocation tasks for the performers. As the methods of research authors used methods of fuzzy rational choice of alternatives: maximin convolution, additive convolutions and fuzzy-production model. These methods are used to assign tasks the automated systems of electronic document management. The main conclusions of the study are: - method based on fuzzy logic inference has shown the best results, most closely consistent with the intuitive representation of an expert on rational choice assignments performers; - maximin convolution method is a pessimistic approach, that does not take into account the good side of the alternatives; - method of additive convolution is an optimistic approach in which low scores on the criteria have the same weight as compared to the high marks that affected its low accuracy. A special contribution to the authors of the study is in developing an effective fuzzy-productions tasks assignment model as well as the implementation of the software system for performing the necessary calculations to evaluate its effectiveness. This determines the scientific novelty and practical value of the study.

Keywords: additive convolution method, maximin convolution method, software package, fuzzyproduction model, decision making, tasks distribution, electronic flow of documents, rational choice of alternatives, fuzzy inference, personal data operator

\section{Введение}

В настоящее время во многих практических областях человеческой деятельности при использовании автоматизированных систем электронного документооборота актуальна задача эффективного распределения различного рода заданий (поручений) от руководителя исполнителям [1,2]. Сложность ее решения обусловлена наличием следующих факторов:

- неопределенностью количества ежедневно возникающих заданий;

- различной сложностью выполнения отдельного задания;

- различным уровнем квалификации и текущей загруженностью исполнителей, выполняющих поступающие задания;

- н необходимостью выполнения заданий в установленные сроки.

Очевидно, что ввиду наличия факторов нечеткости и неопределенности данная задача не имеет однозначного решения [3]. Следовательно, от квалификации руководителя, от правильности принимаемых им решений по распределению заданий исполнителям зависит эффективность его работы, как лица, принимающего решения. Следовательно, в автоматизированных системах электронного документооборота [4], в которых ведущую 
роль по распределению заданий играет человек, актуальна разработка интеллектуальных систем поддержки принятия решений $[5,6]$ для руководителя с целью повышения эффективности (точности) распределения им заданий по исполнителям.

\section{Постановка задачи распределения заданий в автоматизированной системе электронного документооборота}

Рассмотрим автоматизированную систему электронного документооборота, используемую в деятельности территориальных органов Роскомнадзора. С точки зрения защиты прав субъектов персональных данных данная система обеспечивает решение следующих основных задач [7]:

- $\quad$ ведение реестра операторов персональных данных;

- осуществление надзора и контроля за деятельностью операторов персональных данных;

- рассмотрение жалоб и обращений граждан.

Среди перечисленных задач, решаемых в системе электронного документооборота, наиболее трудоемким является ведение реестра операторов персональных данных. Данная задача включает в себя внесение сведений об операторах в единую информационную систему, регистрацию их в реестре, внесение изменений в сведения об операторах, удаление сведений об операторах из реестра, а также предоставление выписки из реестра по запросам заявителей. Особенность решения данной задачи заключается в необходимости оперативной (в течение суток) регистрации поступающих заявлений и внесение актуальных сведений в реестр не позднее 15 суток с момента поступления заявления.

Дадим формальную постановку задачи распределения заданий по ведению реестра операторов персональных данных. Пусть имеется множество заданий $N$, каждое из которых обладает определенным уровнем сложности: низким $\left(S_{1}\right)$, средним $\left(S_{2}\right)$ и высоким $\left(S_{3}\right)$. Также имеется множество исполнителей заданий (альтернатив) $A=\left\{a_{1}, a_{2}, a_{3}, a_{4}\right\}$. Здесь $a_{1}$ - главный специалист-эксперт, $a_{2}$ - ведущий специалист-эксперт, $a_{3}$ - специалист-эксперт, $a_{4}$ - специалиста 1 разряда.

Введем критерии распределения заданий по исполнителям (характеристики исполнителей):

- $\quad C_{1}$ - текущий уровень загруженности исполнителя;

- $\quad C_{2}$ - работоспособность исполнителя;

- $\quad C_{3}$ - уровень квалификации исполнителя.

Требуется решить задачу оптимального распределения заданий с целью поддержки принятия решений руководителя по рациональному выбору исполнителя для каждого из $N$ заданий [8].

Существует большое количество подходов к решению оптимизационных задач [9-12]. Однако, в указанных условиях лицо, принимающее решение, должно учитывать факторы неопределенности, а также нечеткий характер используемых критериев [13]. Следовательно, для решения поставленной задачи необходимо применять нечеткие ме- 
тоды распределения заданий $[14,15]$. В данной работе для решения задачи рационального выбора альтернатив использованы методы максиминной [16] и аддитивной свертки $[17,18]$, а также специально разработанный нечетко-продукционный метод [19], основанный на системе нечеткого логического вывода [20-22].

На базе данных методов и алгоритмов реализован программный комплекс, позволяющий моделировать процессы оптимального распределения заданий по ведению реестра операторов персональных данных. В качестве языка реализации выбран объектно-ориентированный язык программирования $C$ \#. Разработка программного комплекса проводилась в среде Microsoft Visual Studio 2012 IDE.

\section{Структура и состав программного комплекса}

Разработанный программный комплекс имеет модульную структуру и состоит из пяти основных модулей, отвечающих за его настройку, распределение заданий, оценку эффективности принимаемых решений, а также визуализацию получаемых результатов. На рисунке 1 представлена обобщенная структура программного комплекса.

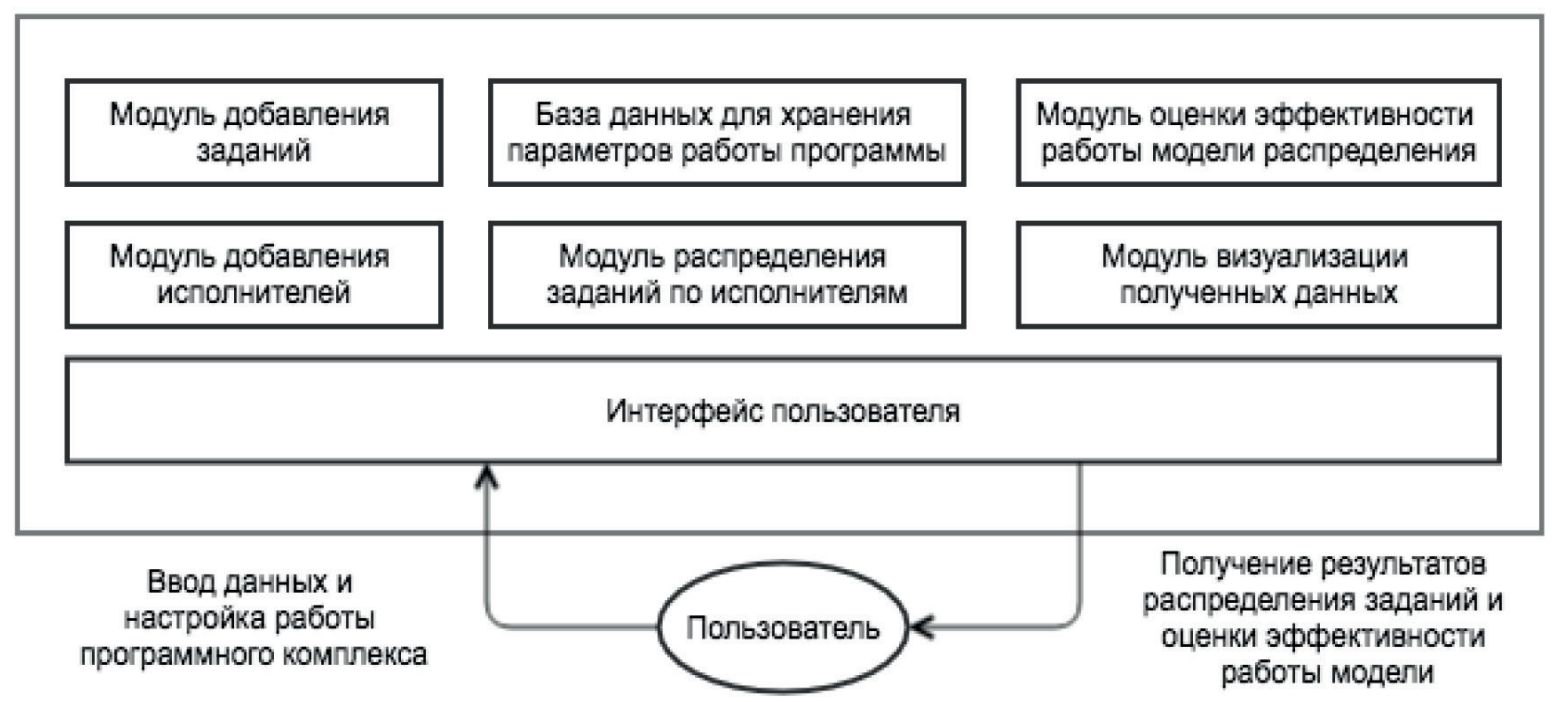

Рис. 1. Структура программного комплекса распределения заданий

Основным компонентом программного комплекса является модуль распределения заданий по исполнителям. Кроме того, в состав программы входят модули добавления заданий и исполнителей, модуль оценки эффективности принимаемых решений, модуль визуализации результатов моделирования, а также локальная база данных для хранения параметров работы программы и реализованных в ней методов.

Модуль распределения заданий состоит из трех независимых подмодулей, каждый из которых реализует отдельный метод распределения заданий. На рисунке 2 представлена структурная схема данного модуля. 


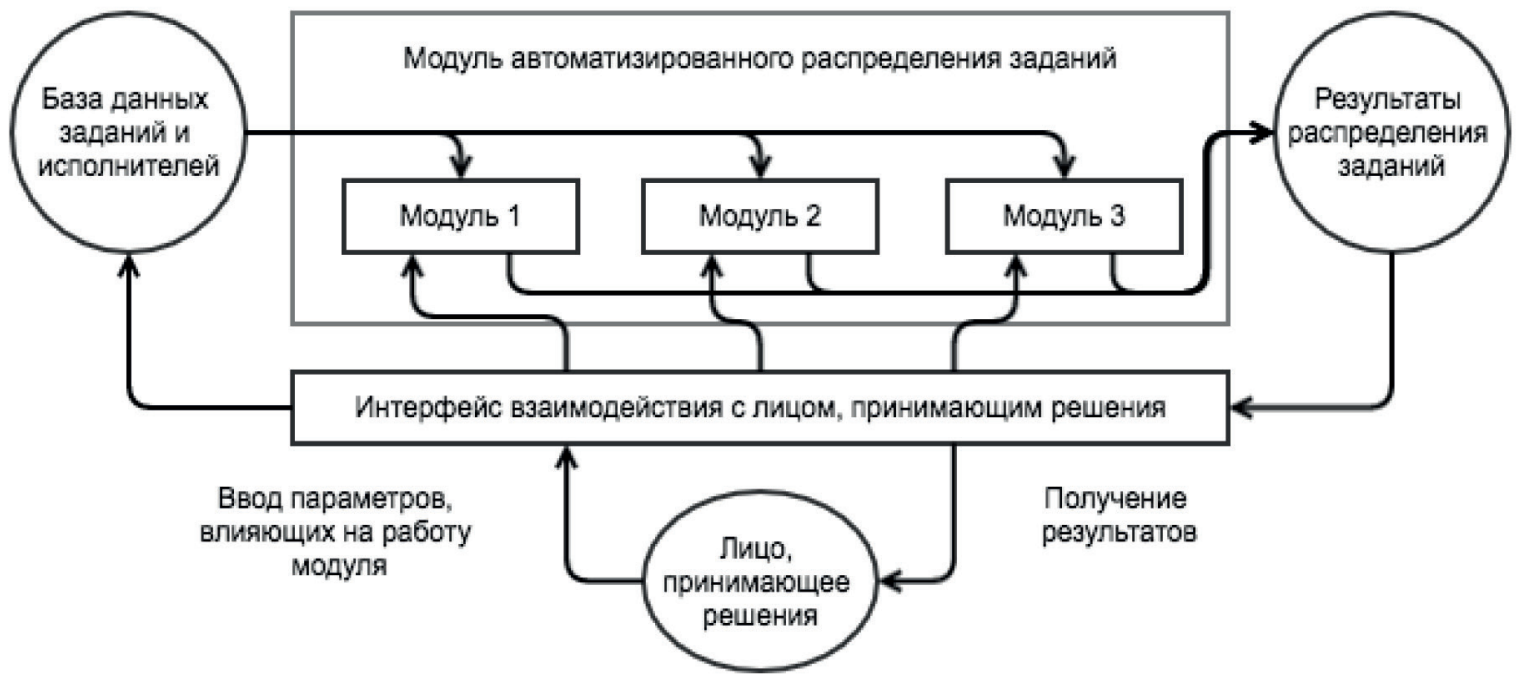

Рис. 2. Структура модуля распределения заданий

Каждый из дополнительных модулей представляет собой реализацию одного из методов распределения заданий: первый модуль реализует метод максиминной свертки, второй модуль - метод аддитивной свертки, третий модуль - метод нечеткого логического вывода. По завершению работы модуля распределения заданий через интерфейс взаимодействия с лицом, принимающим решения, отображаются результаты работы выбранного метода. Затем полученные результаты передаются в модуль оценки эффективности распределения заданий.

На рисунке 3 представлена схема работы модуля оценки точности распределения заданий.

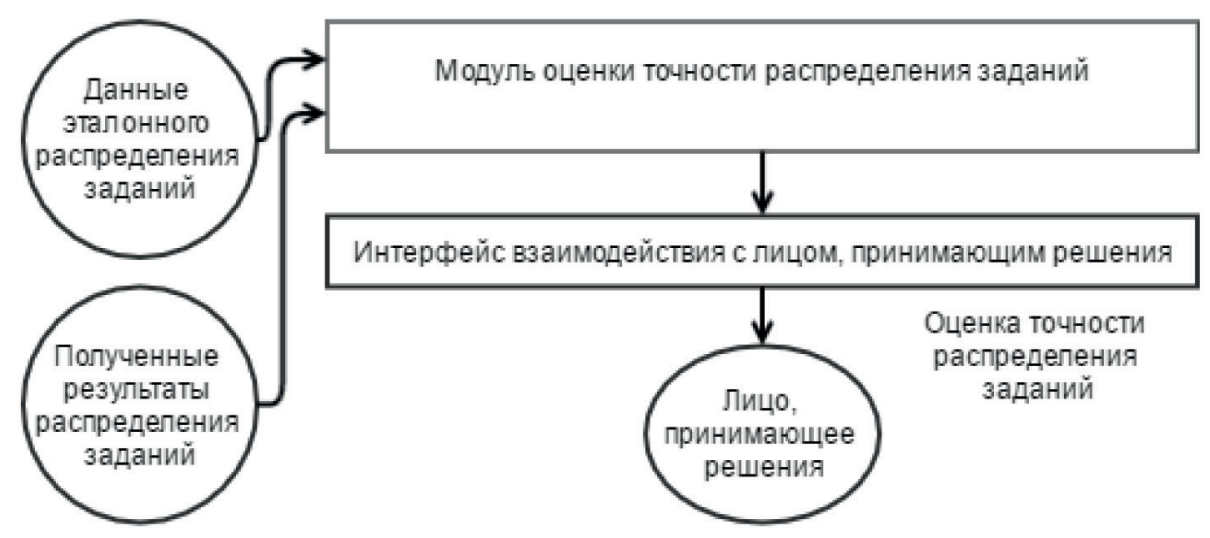

Рис. 3. Функциональная схема работы модуля оценки точности распределения заданий

Данный компонент программного комплекса позволяет сравнивать полученные значения распределения заданий с эталонными и на основе данного сравнения формирует оценку согласованности метода распределения заданий с экспертной моделью. 
Рассмотрим функционирование программного комплекса на примере распределения произвольного набора заданий с использованием метода нечеткого логического вывода.

\section{Пример функционирования программного комплекса}

Работа программы начинается с этапа подготовки характеристик исполнителей для последующего использования этих данных в алгоритмах распределения заданий. На рисунке 4 представлен блок управления исполнителями и визуализации их актуальных данных.

\begin{tabular}{l} 
Сотрудники \\
\begin{tabular}{|c|l|l|l|l|}
\hline & Должность & Загруженность & $\begin{array}{l}\text { Начальное } \\
\text { количество } \\
\text { заданий }\end{array}$ & $\begin{array}{l}\text { Tекущее } \\
\text { количесто } \\
\text { заданий }\end{array}$ \\
\hline 1 & ГлавнЕй специа... & $0 \%$ & 0 & 0 \\
\hline 2 & Ведущий специа... & $0 \%$ & 0 & 0 \\
\hline 3 & Специалист-экс... & $0 \%$ & 0 & 0 \\
\hline 4 & Специалист пер... & $0 \%$ & 0 & 0 \\
\hline
\end{tabular} \\
\hline
\end{tabular}

Рис. 4. Внешний вид блока управления исполнителями и визуализации их актуальных данных

В данном окне имеется возможность добавления исполнителей, а также редактирования их данных. В таблице показывается текущая загруженность каждого исполнителя, начальное и текущее количество заданий. После актуализации данных по каждому исполнителю необходимо перейти к добавлению заданий для последующего их распределения. Для этого необходимо перейти в окно генератора заданий, представленное на рисунке 5.

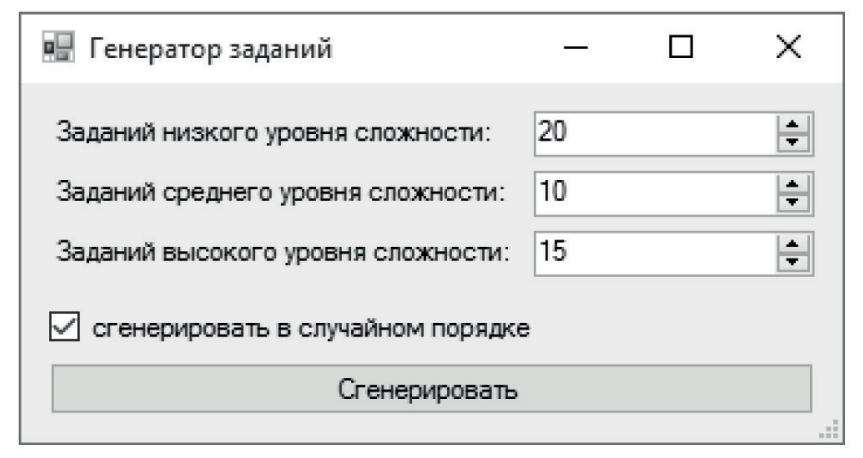

Рис. 5. Внешний вид окна генератора заданий

В этом окне необходимо задать количество заданий низкого, среднего и высокого уровня сложности. Также есть возможность генерации заданий в случайном порядке. В этом случае сгенерированные задания будут перемешаны. 
После генерации заданий необходимо перейти к окну корректировки весов критериев, которые используются в работе методов распределения заданий. От точности задания весовых коэффициентов будет зависеть согласованность конечных результатов с экспертной моделью распределением заданий.

На рисунке 6 представлено окно корректировки весов критериев.

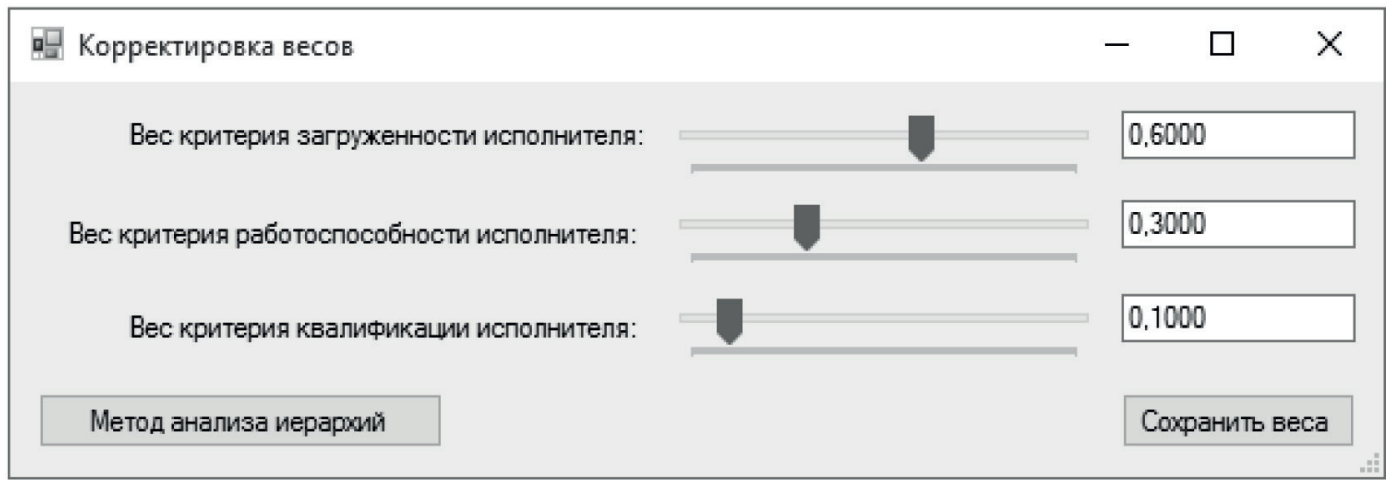

Рис. 6. Внешний вид окна корректировки весов критериев

Как видно из данного рисунка веса критериев можно задавать как вручную, так и с использованием метода анализа иерархий [23]. В последнем случае эксперту необходимо сравнить все критерии между собой по шкале парных сравнений, после чего веса критериев рассчитаются автоматически.

После выбора метода и настройки программы можно приступать к распределению заданий. В программном комплексе предусмотрено два варианта их распределения - по одному заданию (интерактивный вариант) и распределение всех заданий сразу. В любом случае в журнале распределения заданий, приведенном на рисунке 7, отобразятся данные по последнему распределению.

\begin{tabular}{|c|c|c|c|c|c|c|c|c|c|c|c|}
\hline & $\begin{array}{l}\text { Уровень } \\
\text { сложности } \\
\text { задания }\end{array}$ & $\begin{array}{l}\text { 3агруж } \\
\text { 1го }\end{array}$ & $\begin{array}{l}\text { 3агруж } \\
\text { 2ro }\end{array}$ & $\begin{array}{l}\text { 3агруж } \\
\text { 3-го }\end{array}$ & $\begin{array}{l}\text { 3агруж } \\
\text { 4-го }\end{array}$ & Исполнитель & $\begin{array}{l}\text { Число } \\
\text { заданий } \\
1 \text {-го }\end{array}$ & $\begin{array}{l}\text { Число } \\
\text { заданий } \\
\text { 2-го }\end{array}$ & $\begin{array}{l}\text { Число } \\
\text { заданий } \\
\text { 3го }\end{array}$ & $\begin{array}{l}\text { Число } \\
\text { заданий } \\
\text { 4-го }\end{array}$ & ^ \\
\hline 35 & Низкий & $60 \%$ & $45 \%$ & $25 \%$ & $50 \%$ & 3 & 12 & 9 & 5 & 10 & \\
\hline 36 & Средний & $60 \%$ & $50 \%$ & $25 \%$ & $50 \%$ & 2 & 12 & 10 & 5 & 10 & \\
\hline 37 & Средний & $60 \%$ & $50 \%$ & $30 \%$ & $50 \%$ & 3 & 12 & 10 & 6 & 10 & \\
\hline 38 & Низкий & $60 \%$ & $50 \%$ & $30 \%$ & $55 \%$ & 4 & 12 & 10 & 6 & 11 & \\
\hline 39 & Средний & $65 \%$ & $50 \%$ & $30 \%$ & $55 \%$ & 1 & 13 & 10 & 6 & 11 & \\
\hline 40 & Низкий & $65 \%$ & $50 \%$ & $35 \%$ & $55 \%$ & 3 & 13 & 10 & 7 & 11 & \\
\hline 41 & Низкий & $65 \%$ & $50 \%$ & $35 \%$ & $60 \%$ & 4 & 13 & 10 & 7 & 12 & \\
\hline 42 & Высокий & $65 \%$ & $55 \%$ & $35 \%$ & $60 \%$ & 2 & 13 & 11 & 7 & 12 & \\
\hline 43 & Высокий & $65 \%$ & $60 \%$ & $35 \%$ & $60 \%$ & 2 & 13 & 12 & 7 & 12 & \\
\hline 44 & Средний & $65 \%$ & $60 \%$ & $40 \%$ & $60 \%$ & 3 & 13 & 12 & 8 & 12 & \\
\hline
\end{tabular}

Рис. 7. Фрагмент журнала распределения заданий 
После распределения всех заданий можно открыть окно результатов и посмотреть загруженность каждого исполнителя. Таким образом, на данном этапе завершается функционирование программного комплекса, позволяющего в автоматизированном режиме распределять задания по исполнителям на основе нечетких методов принятия решений.

\section{Оценка эффективности распределения заданий на базе программного комплекса}

Для оценки эффективности распределения заданий на базе разработанного программного комплекса использованы реальные данные, накопленные в системе электронного документооборота Территориального органа Роскомнадзора по Республике Татарстан [7]. В таблице 1 представлен фрагмент исходных данных, соответствующих экспертной модели распределения заданий.

Табл. 1. Фрагмент экспертных данных по распределению заданий

\begin{tabular}{|c|c|c|c|c|c|c|}
\hline \multirow{2}{*}{$\begin{array}{l}\text { № } \\
\pi / \Pi\end{array}$} & \multirow{2}{*}{$\begin{array}{c}\text { Уровень } \\
\text { сложности } \\
\text { задания }\end{array}$} & \multicolumn{4}{|c|}{ Число заданий у исполнителей } & \multirow{2}{*}{$\begin{array}{c}\text { Исполнитель } \\
\text { задания }\end{array}$} \\
\hline & & a1 & a2 & a3 & a4 & \\
\hline 1 & высокий & 14 & 16 & 14 & 6 & a1 \\
\hline 2 & высокий & 15 & 16 & 14 & 6 & a3 \\
\hline 3 & низкий & 15 & 16 & 15 & 6 & a4 \\
\hline 4 & средний & 15 & 16 & 15 & 7 & a4 \\
\hline 5 & средний & 15 & 16 & 15 & 8 & a4 \\
\hline 6 & средний & 15 & 16 & 15 & 9 & a4 \\
\hline 7 & высокий & 15 & 16 & 15 & 10 & a3 \\
\hline 8 & высокий & 15 & 16 & 16 & 10 & a3 \\
\hline 9 & высокий & 15 & 16 & 17 & 10 & a3 \\
\hline 10 & высокий & 15 & 16 & 18 & 10 & a3 \\
\hline
\end{tabular}

Тестовая выборка включала 74 задания, из которых 55 заданий высокого, 18 заданий среднего и 1 задание низкого уровня сложности. Причем, первому исполнителю эксперт распределил 20 заданий высокого уровня сложности, второму исполнителю - 18 заданий высокого уровня сложности, третьему исполнителю - 17 заданий высокого и 3 задания среднего уровня сложности, четвертому - 15 заданий среднего и 1 задание низкого уровня сложности.

В результате экспериментальных исследований проведено сравнение работы методов распределения заданий и степени согласованности результатов их работы с результатами, полученными экспертом. На рисунке 8 представлены результаты распределения заданий на основе метода максиминной свертки. 


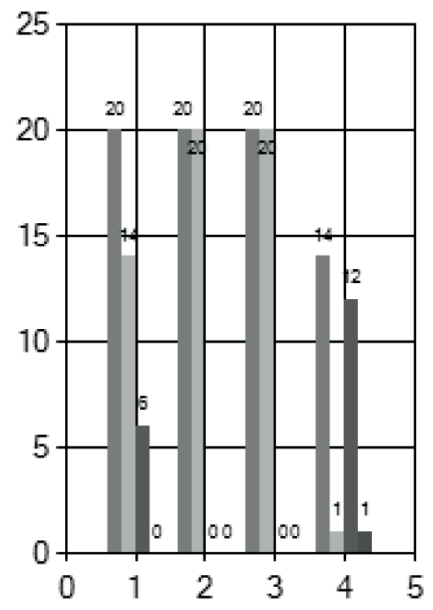

Bce задания

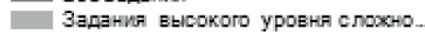

Задания среднего уровна слихно.

Задания низкого уровнэ слохности

Boero заданий: 74

Ваданий выюокого уроеня спокности: 55

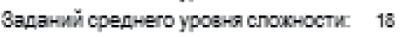

Baданий низкопо уроена спокности: 1

Точность распределения:

$83,78 \%$

Рис. 8. Результаты работы метода максиминной свертки

Как видно из рисунка, точность распределения заданий на основе данного метода составляет 83,78\%, что является достаточно высоким результатом. Однако, данный метод достаточно равномерно распределяет задания различного уровня сложности по всем исполнителям, независимо от их квалификации, что не вполне согласуется с экспертным подходом к распределению заданий.

На рисунке 9 представлены результаты распределения заданий на основе метода аддитивной свертки.

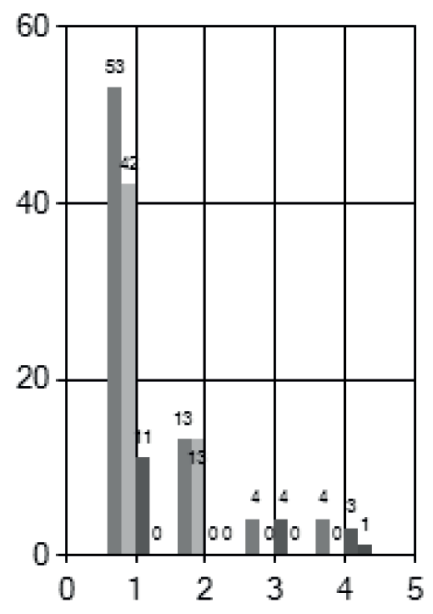

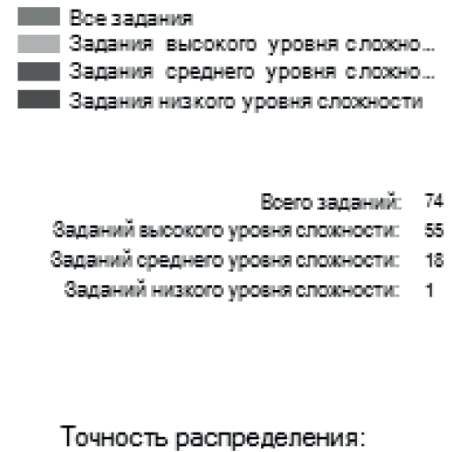

$54,05 \%$

Рис. 9. Результаты работы метода аддитивной свертки

Особенностью данного метода является то, что он максимально загружает сильного исполнителя. Реализация данного метода не учитывает перегруженности исполнителей. Точность распределения заданий на основе метода аддитивной свертки составляет $54,05 \%$. 
На рисунке 10 представлены результаты распределения заданий на основе нечеткопродукционной модели.
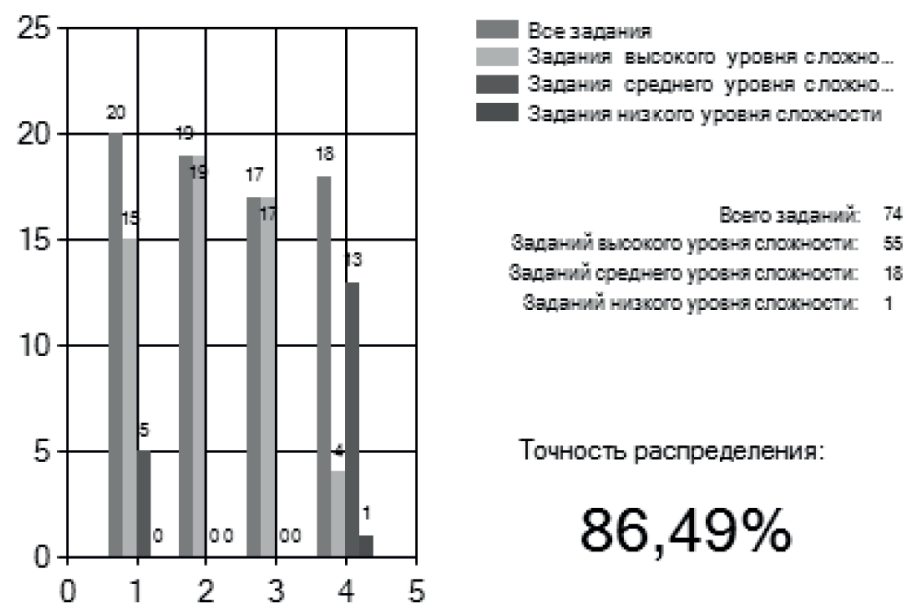

Точность распределения:

\section{$86,49 \%$}

Рис. 10. Результаты работы нечетко-продукционной модели

Как видно из рисунка, метод нечеткого логического вывода распределяет задания наиболее точно. Этот метод также хорошо работает в условиях перегруженности исполнителей.

Таким образом, метод на основе нечеткого логического вывода показал результаты, наиболее точно согласующиеся с интуитивным представлением эксперта по рациональному выбору исполнителей заданий. В основу данного метода положен эвристический подход, основанный на нечетко-продукционных правилах. Метод максиминной свертки является пессимистичным подходом, не учитывающим хорошие стороны альтернатив. В данном методе лучшей считается альтернатива, имеющая минимальные недостатки по всем критериям. Метод аддитивной свертки реализует оптимистичный подход, в котором низкие оценки по критериям имеют одинаковый вес по сравнению с высокими оценками.

\section{Заключение}

Результаты проведенных исследований показали устойчивость описанных методов и согласованность получаемых решений с мнением экспертов. Разработан программный комплекс для поддержки принятия решений при распределении заданий по ведению реестра операторов персональных данных. Планируется внедрение и практическое использование программного комплекса в составе систем электронного документооборота Управления Роскомнадзора по Республике Татарстан, а также Учебно-научного центра информационной безопасности. Это позволит повысить качество принимаемых решений за счет применения эффективных методов рационального выбора альтернатив. 


\section{Библиография :}

1. Ивченко В.Д., Корнеев А.А. Анализ методов распределения заданий в задаче управления коллективом роботов // Мехатроника, автоматизация, управление. - 2009. - № 7. - С. 36-42.

2. Ченцов П.А. 0 задаче распределения заданий между участниками с ограничениями на выбор заданий // Вестник компьютерных и информационных технологий. - 2007. - № 7. - С. 52-56.

3. Лотов А.В., Поспелова И.И. Многокритериальные задачи принятия решения: Учеб. пособие. - М: МАКС Пресc, 2008. - 197 c.

4. Трегубов В.М., Катасёв А.С., Кириллов А.Е., Алексеев А.А. Информационная технология анализа и классификации электронных документов / Поиск эффективных решений в процессе создания и реализации научных разработок в российской авиационной и ракетно-космической промышленности. Международная научно-практическая конференция. Казань. - 2014. - С. 345-348.

5. Катасёв А.С., Катасёва Д.В. Интеллектуальный анализвременных рядов в системахдиагностики иподдержки принятия решений / Поиск эффективных решений в процессе создания и реализации научных разработок в российской авиационной и ракетно-космической промышленности Международная научно-практическая конференция. Казань. - 2014. - С. 481-483.

6. Чернов В.Г. Модели поддержки принятия решений в инвестиционной деятельности на основе аппарата нечетких множеств. - М.: Горячая линия - Телеком, 2006. - 255 с.

7. Аникин И.В., Кирпичников А.П., Талипов Н.Г. Оценка эффективности деятельности уполномоченного органа по защите прав субъектов персональных данных // Вестник Казанского технологического университета. - 2015. - T. 18. - № 1. - С. 279-281.

8. Змеев С.А., Селютин И.Н., Скрыль Е.Б., Никитин А.А. Рациональный выбор средств защиты при структурном синтезе программных систем защиты информации в системах электронного документооборота // Вестник Воронежского института ФСИН России. - 2013. - № 2. - С. 55-59.

9. Алексеев А.А., Кораблев Ю.А., Шестопалов М.Ю. Идентификация и диагностика систем. - М: Издательский центр «Академия», 2009. - 351 с.

10. Глова В.И., Катасёв А.С., Корнилов Г.С. Преднастройка и оптимизация параметров нечеткой нейронной сети при формировании баз знаний экспертных систем // Информационные технологии. - 2010. - № 5. - C. 15-19.

11. Емалетдинова Л.Ю., Кайнов А.С. Дискретная нейросетевая модель оптимизации распределения заданий по нескольким компьютерам // Вестник Казанского государственного технического университета им. А.Н. Туполева. - 2007. - №1(46). - С. 80-83.

12. Катасёв А.С., Абдулхаков А.Р. Редукция нечетких правил в задаче оптимизации баз знаний экспертных систем // Вестник Казанского государственного технического университета им. А.Н. Туполева. - 2012. - № 3. - C. 110-115.

13. Абдулхаков А.Р., Катасёв А.С. Кластерно-генетический метод редукции баз знаний интеллектуальных систем // Фундаментальные исследования. - 2015. - № 5-3. - С. 471-475. 
14. Демидова Л.А. Развитие методов теории нечетких множеств и генетических алгоритмов для задач поддержки принятия решений в условиях неопределенности: теоретико-методологическое исследование. Автореферат диссертации на соискание ученой степени докт. техн. наук. - Рязань, 2009. - 39 с. .

15. Катасёв А.С. Модели и методы формирования нечетких правил в интеллектуальных системах диагностики состояния сложных объектов // Диссертация на соискание ученой степени доктора технических наук / Казанский национальный исследовательский технологический университет. Казань, 2014. - 256 с.

16. Демидова Л.А. Развитие методов теории нечетких множеств и генетических алгоритмов для задач поддержки принятия решений в условиях неопределенности: теоретико-методологическое исследование. Автореферат диссертации на соискание ученой степени докт. техн. наук. - Рязань, 2009. - 39 с.

17. Постников В.М., Спиридонов С.Б. Многокритериальный выбор варианта решения на основе аддитивной свертки показателей, являющихся членами арифметических прогрессий // Наука и образование: научное издание МГТУ им. Н.Э. Баумана. 2015. № 11. С. 443-464.

18. Черноруцкий И.Г. Методы принятия решений. - СПб.: БХВ-Петербург, 2005. - 416 с.

19. Ковалев С.М., Лященко А.М. Нечетко-продукционная модель оценки ходовых свойств отцепов на основе перцептивного анализа временных рядов // Актуальные вопросы современной науки. - 2013. - № 30-2. - C. 17-26.

20. Катасёв А.С. Математическое и программное обеспечение формирования баз знаний мягких экспертных систем диагностики состояния сложных объектов: монография. - Казань: «Республиканский центр мониторинга качества образования», 2013. - 200 с., ил.

21. Катасёв А.С., Газимова Д.Р. Инвариантная нечетко-продукционная модель представления знаний в экспертных системах // Вестник Казанского государственного технического университета им. А.Н. Туполева. - 2011. - №1. - C. 142-148.

22. Катасёв А.С., Емалетдинова Л.Ю. Нечетко-продукционная каскадная модель диагностики состояния сложного объекта // Программные системы и вычислительные методы. - 2013. - № 1. - С. 69-81.

23. Илларионов М.Г. Применение метода анализа иерархий в принятии управленческих решений // Актуальные проблемы экономики и права. - 2009. - № 1. - С. 37-42.

\section{References:}

1. Ivchenko V.D., Korneev A.A. Analiz metodov raspredeleniya zadanii v zadache upravleniya kollektivom robotov // Mekhatronika, avtomatizatsiya, upravlenie. - 2009. - № 7. - S. 36-42.

2. Chentsov P.A. 0 zadache raspredeleniya zadanii mezhdu uchastnikami s ogranicheniyami na vybor zadanii // Vestnik komp'yuternykh i informatsionnykh tekhnologii. - 2007. - № 7. - S. 52-56.

3. Lotov A.V., Pospelova I.I. Mnogokriterial'nye zadachi prinyatiya resheniya: Ucheb. posobie. - M: MAKS Press, 2008. $-197 \mathrm{~s}$.

4. Tregubov V.M., Katasev A.S., Kirillov A.E., Alekseev A.A. Informatsionnaya tekhnologiya analiza i klassifikatsii elektronnykh dokumentov / Poisk effektivnykh reshenii v protsesse sozdaniya i realizatsii nauchnykh razrabotok v rossiiskoi aviatsionnoi i raketno-kosmicheskoi promyshlennosti. Mezhdunarodnaya nauchno-prakticheskaya konferentsiya. Kazan'. - 2014. - S. 345-348. 
5. Katasev A.S., Kataseva D.V. Intellektual'nyi analiz vremennykh ryadov v sistemakh diagnostiki i podderzhki prinyatiya reshenii / Poisk effektivnykh reshenii v protsesse sozdaniya i realizatsii nauchnykh razrabotok v rossiiskoi aviatsionnoi i raketno-kosmicheskoi promyshlennosti Mezhdunarodnaya nauchno-prakticheskaya konferentsiya. Kazan'. - 2014. - S. 481-483.

6. Chernov V.G. Modeli podderzhki prinyatiya resheniĩ v investitsionnoĭ deyatel'nosti na osnove apparata nechetkikh mnozhestv. - M.: Goryachaya liniya - Telekom, 2006. - 255 s.

7. Anikin I.V., Kirpichnikov A.P., Talipov N.G. Otsenka effektivnosti deyatel'nosti upolnomochennogo organa po zashchite prav sub"ektov personal'nykh dannykh // Vestnik Kazanskogo tekhnologicheskogo universiteta. - 2015. - T. 18. - № 1. - S. 279-281.

8. Zmeev S.A., Selyutin I.N., Skryl'E.B., Nikitin A.A. Ratsional'nyi vybor sredstv zashchity pri strukturnom sinteze programmnykh sistem zashchity informatsii v sistemakh elektronnogo dokumentooborota // Vestnik Voronezhskogo instituta FSIN Rossii. - 2013. - № 2. - S. 55-59.

9. Alekseev A.A., Korablev Yu.A., Shestopalov M.Yu. Identifikatsiya i diagnostika sistem. - M: Izdatel'skii tsentr «Akademiya», 2009. $-351 \mathrm{~s}$.

10. Glova V.I., Katasev A.S., Kornilov G.S. Prednastroika i optimizatsiya parametrov nechetkoi neironnoi seti pri formirovanii baz znanii ekspertnykh sistem // Informatsionnye tekhnologii. - 2010. - № 5. - S. 15-19.

11. Emaletdinova L.Yu., Kainov A.S. Diskretnaya neirosetevaya model' optimizatsii raspredeleniya zadanii po neskol'kim komp'yuteram // Vestnik Kazanskogo gosudarstvennogo tekhnicheskogo universiteta im. A.N. Tupoleva. - 2007. - №1(46). - S. 80-83.

12. Katasev A.S., Abdulkhakov A.R. Reduktsiya nechetkikh pravil v zadache optimizatsii baz znanii ekspertnykh sistem // Vestnik Kazanskogo gosudarstvennogo tekhnicheskogo universiteta im. A.N. Tupoleva. - 2012. - № 3. - S. 110-115.

13. Abdulkhakov A.R., Katasev A.S. Klasterno-geneticheskii metod reduktsii baz znanii intellektual'nykh sistem // Fundamental'nye issledovaniya. - 2015. - № 5-3. - S. 471-475.

14. Demidova L.A. Razvitie metodov teorii nechetkikh mnozhestv i geneticheskikh algoritmov dlya zadach podderzhki prinyatiya resheniĭ v usloviyakh neopredelennosti: teoretiko-metodologicheskoe issledovanie. Avtoreferat dissertatsii na soiskanie uchenoi stepeni dokt. tekhn. nauk. - Ryazan', 2009. - 39 s.

15. Katasev A.S. Modeli i metody formirovaniya nechetkikh pravil v intellektual'nykh sistemakh diagnostiki sostoyaniya slozhnykh ob"ektov // Dissertatsiya na soiskanie uchenoi stepeni doktora tekhnicheskikh nauk / Kazanskii natsional'nyi issledovatel'skii tekhnologicheskii universitet. Kazan', 2014. - 256 s.

16. Rzaev R.R., Dzhamalov Z.R., Babaeva S.T., Rzaeva I.R. Otsenka finansovoi ustoichivosti kommercheskikh bankov nechetkim metodom maksiminnoi svertki i ikh ranzhirovanie // Matematicheskie mashiny i sistemy. - 2016. - № 1. - S. 79-88.

17. Postnikov V.M., Spiridonov S.B. Mnogokriterial'nyi vybor varianta resheniya na osnove additivnoi svertki pokazatelei, yavlyayushchikhsya chlenami arifmeticheskikh progressii // Nauka i obrazovanie: nauchnoe izdanie MGTU im. N.E. Baumana. 2015. № 11. S. 443-464.

18. Chernorutskii I.G. Metody prinyatiya reshenii. - SPb.: BKhV-Peterburg, 2005. - 416s.

19. Kovalev S.M., Lyashchenko A.M. Nechetko-produktsionnaya model' otsenki khodovykh svoistv ottsepov na osnove pertseptivnogo analiza vremennykh ryadov // Aktual'nye voprosy sovremennoi nauki. - 2013. - № 30-2. - S. 17-26. 
20. Katasev A.S. Matematicheskoe i programmnoe obespechenie formirovaniya baz znanii myagkikh ekspertnykh sistem diagnostiki sostoyaniya slozhnykh ob"ektov: monografiya. - Kazan': «Respublikanskii tsentr monitoringa kachestva obrazovaniya», 2013. - 200 s., il.

21. Katasev A.S., Gazimova D.R. Invariantnaya nechetko-produktsionnaya model' predstavleniya znanii v ekspertnykh sistemakh // Vestnik Kazanskogo gosudarstvennogo tekhnicheskogo universiteta im. A.N. Tupoleva. - 2011. - №1. -S. 142-148.

22. Katasev A.S., Emaletdinova L.Yu. Nechetko-produktsionnaya kaskadnaya model' diagnostiki sostoyaniya slozhnogo ob"ekta // Programmnye sistemy i vychislitel'nye metody. - 2013. - № 1. - S. 69-81.

23. Illarionov M.G. Primenenie metoda analiza ierarkhii v prinyatii upravlencheskikh reshenii // Aktual'nye problemy ekonomiki i prava. - 2009. - № 1. - S. 37-42.. 